\title{
Economic Viability of Sustainable Land Management: Are Local Farmers Aware About the Costs and Benefits?
}

\author{
Mamoudou Ibrahima Sall ${ }^{*} \quad$ Yang Shu ${ }^{2}$ \\ 1.School of Economics, Huazhong University of Science and Technology, 1037 Luoyu Road, Wuhan, 430074, \\ P.R. China \\ 2.School of Economics and Trade, Hunan University, Lushan S. RD, Changsha, Hunan, China
}

\begin{abstract}
The sustainable land management (SLM) is the important parameter to efficiently manage the farm-related practices in order to get the maximum benefits. The economic viability of SLM elucidated the efficient cost/benefit analysis that was the dire need. All around the globe, the practice of sustainable land management is being executed for different purposes such as rehabilitating dry areas, minimizing the effect of degradation and also saving and maintaining the sustainability of natural resources. The purpose of this study is to identify the costs of SLM, to analyze the benefits of SLM and then to compare both of them with each other to recognize its economic viability. The quantitative methods are acquired with the help of a questionnaire; data is collected from the people of Mali. The quantification of the data revealed the considerable experience as well engagement of people in SLM by well knowing its costs and benefits to sake more profit. The rented land farmers were more enthusiastic in applying SLM than landowners. Although the cost of farming practice was increased aggregate of farming outputs increased more proportionally than farming cost. The overall advantages of increased income diversity, economic disparities, long-term returns, short-term returns and farm management as well the decrease in farm workload were found. The aggregate findings will help the farmers to increase their profits and productivity. The empirical evidence will also help the government to put SLM into practice and another researcher to further figure out the problems by keeping this study as a reference.
\end{abstract}

Keywords: Sustainable land management, economic viability, costs, benefits, analysis

DOI: $10.7176 / \mathrm{JESD} / 10-24-04$

Publication date: December $31^{\text {st }} 2019$

\section{Introduction}

Sustainable land management is a practice of managing the land, soil, animals, plants and water efficiently to meet the changing needs and wants of the people while retaining the sustainability of all these resources. It looks after all the activities which are concerned with SLM such as mining, farming, estate and property management and planning of forming housing schemes in towns(Duval, Galantini, Martínez, López, \& Wall, 2016). SLM covers the measures of vegetation, water and soil conservation to get the goal of increased productivity. Moreover the protection of natural resources within the boundaries of economic viability are also the key components of SLM (Schwilch et al., 2014). Many countries all across the world is opting for sustainable land management (SLM) due to various reasons (Almagro et al., 2016).

The economic benefits as well as the costs of SLM has been investigated in the past and the economic and environmental benefits have been achieved through SLM. The SLM starts from within the individual as millions of farmers have to take initiative to preserve the natural resources for present as well as for future generations (Giger, Liniger, Sauter, \& Schwilch, 2018). By using the SLM, degradation is minimized and also dry areas are rehabilitated. Moreover, it serves to ensure that natural resources are used efficiently and effectively. Farmers get great benefits by using terracing practice as it helps to retain good soil. Moreover, the construction of bunds and terraces are in accordance with the area specifications. Besides, it also helps the farmers to enhance the productivity of their farms and increase the quantity of fruits and vegetables such as watermelon, bananas, mangoes, strawberries, lemons, carrots, spinach, ginger and onions etc. respectively (Gray, Chapman, \& Murphy, 2015). However, the cost of soil erosion cannot be ignored either.

The labor's opportunity cost and cost of credit are in accordance with the specific area (Bertin, Zacharie, Ann, Ebenezar, \& Alain, 2014). However, the unavailability of credit may inhibit the practices of sustainable land management adapted by farmers in rural areas. Moreover, the return is expected to be yielded after a longer period of time so farmers cannot wait that long to fulfill their needs. In addition, farmers may not have enough capital for SLM so they need external loans from lending institutions, which means that cost of borrowing is also incurred (Halbac-Cotoara-Zamfir, Herban, Petursdottir, \& Finger, 2017).

Despite of the fact that a lot of work has already been done on SLM but still it is not clear if the costs of SLM are higher than its benefits. This is the reason why people all over the world resist this practice and think that if they opt this practice then maybe they have to bear heavy costs. This problem exists in Mali that's why this research is been conducted. However, previous studies (Kapur, Eswaran, \& Blum, 2014) have demonstrated that this problem is not common domestically but also globally. In order to save the natural resources, people think of 
adapting the practice of sustainable land management but they are not aware of its benefits and costs (Keesstra et al., 2016). However, if in near future, this problem is not resolved then people may lose their natural resources on account of different reasons. This paper will elaborate the costs and benefits of sustainable land management along with its concept and approaches.

Previously much work has been done on the implications of the sustainable land management but nothing has been worked on its cost analysis by the researchers. A number of benefits and costs are found out related to SLM. Different investigators (Kundzewicz \& Kowalczak, 2014) who have worked on this subject have done the qualitative study on this wide topic. But they did not analyze the quantitative study on this topic. So, in this research paper, quantitative analysis will be conducted to know the cost and benefit analysis of SLM according to the economy of Mali. As the economic condition of every nation is different so the external and internal factors affecting the decision of applying the activity of SLM is also different (Liniger, Mekdaschi, Moll, \& Zander, 2017). Moreover, the economic viability of sustainable land management in Mali has also been elaborated.

By considering the research gap of quantitative evaluation of actual and perceived costs and benefits of SLM practices, the cost and benefit analysis of sustainable land management is the main purpose of this study. The objectives are to identify the costs of sustainable land management, to analyze the benefits of sustainable land management and to compare the costs and benefits of sustainable land management. The theoretical significances of this study may help the people all around the world to compare the costs and benefits of sustainable land management. The findings may use as reference for land management related studies by reporting the aspects of sustainable land management to increase the empirical evidence regarding SLM. The practical significance of sustainable land management may guide farmers to analyze its costs and benefits thoroughly and then take a decision according to it whether they should implement the practice of SLM or not. Moreover, by using the techniques of SLM, flood can also be controlled and avoided. As the cost and benefits of sustainable land management are not analyzed before, so government can see its costs and benefits through this study to form policies related to SLM.

\section{Literature Review}

The different definitions, types, concept, approaches, costs and benefits of sustainable land management has been discussed in this section. The sustainable land management refer to the effective management of land with zero effect on its ecological and biodiversity processes. The biodiversity consists of living organisms, both human beings and animals, ecosystems and plants. The ecological integrity means the natural environment is able to defend itself against external forces such as depletion of ozone layer. The natural capital which includes ocean, fresh air, fresh water, forests, conservation of soil etc. are essential to be maintained for the survival of living organisms (Maisharou, Chirwa, Larwanou, Babalola, \& Ofoegbu, 2015; Marques et al., 2015).

The economic viability of SLM depends on a number of factors such as income, expenditures, stability of earnings, output generated on farm, nature and quality. The concept of SLM has been elaborated in previous studies to encompass different methods such as demolishing tropical forests, using artificial agriculture systems and expansion of urban areas, humans are changing the earth's landscapes (Nkonya \& Pender, 2015). However, the practices adapted by people regarding land-use are different in every part of the world but their ultimate result may remain identical, like acquiring natural resources to fulfill the needs on immediate basis and producing fiber and food for a growing population.

The sustainable land management is crucial for fulfilling the needs and desires of human beings and animals and also for marinating the natural ecosystem of the world (Mutoko, Hein, \& Shisanya, 2014). If land is handled improperly then many negative consequences arise such as degradation of land and climate change and as well as the lower production of food and services. Nonetheless, many costs incur when applying the strategy of SLM such as opportunity cost of labor and credit cost of labor.

From the last few decades, researchers have found out that farmers and land managers have got successful in increasing the food per capita and in reducing the prices of food (Plieninger et al., 2015). All these activities are done through the awareness of technologies and new methods. But recently it has been viewed that in developed areas of the world, the increment in the productivity of agriculture sector has decreased the prices of commodities which in turn lowers the profit margins of farmers in economic way. Yet, these factors may not be valid for future and also what is sustainable now may not be sustainable in future and moreover, sustainability of land varies from area to area.

There are few objectives on which the structure of sustainable land management stands such as protection, acceptability, viability, security and productivity. Literature has described that productivity is getting the return from SLM by using the land proficiently and by enhancing its productivity. Past studies (Pereira et al., 2017) have explained viability that if the land is not economically viable then it cannot be survived for too long. Then researchers have said that natural resources and species of plants and animals must be protected carefully for future generations. Moreover, the level of production risk should be reduced and capacity of soil should be enhanced. At last, the land used must be socially acceptable (Pidlisnyuk, Erickson, Kharchenko, \& Stefanovska, 2014). Yet 
these objectives are not being executed proficiently.

The SLM involves different activities such as enhancing and preserving the production functions of forestland, cropland and grazing land like flatlands, upland areas, bottomlands and down-slope regions. Then it also helps to sustain the productive areas of forest and also commercial as well as noncommercial reserves of the forests. Moreover, it also ensures to maintain the needs of hydropower generation and zones of water conservation (Sanz et al., 2017). In addition, the needs of farms and other activities of production are also maintained by aquifers. Nevertheless, it is not yet analyzed if its costs are lower than is benefits.

Moreover, SLM has also other techniques for reserving and discontinuing the degradation of land and also to reverse the negative side effects which are caused by misuse of productive activities. These actions are very crucial in some specific areas especially in those areas where there is a lot of pressure from residents and where upland degradation has destructed the area such as in watersheds and uplands (Reed et al., 2015). Yet, the negative results cannot be only controlled by SLM.

Sustainable land management has different principles which are as follows. It comprises of participatory approaches and land user driven; using the natural resources of the planet in integrated way to protect the ecosystem and farming methods; involvement of multi stakeholders and multilevel and support of institutions such as generation of income at local level (Brevik et al., 2017). However, all these principles may not be implemented efficiently.

Day by day, the use of land and natural resources consumption are increasing in the whole world because of different reasons such as changing climate, growing population, social status of changing population, increasing prices of products. All these reasons lead towards the excessive use of land, which further results in the shortage of land. The approaches for these issues need to be combined and interlinked successfully in the areas of agriculture, forestry, water management and urban planning. Through these approaches, land can be sustained effectively (Teshome, de Graaff, Ritsema, \& Kassie, 2016; Wichelns \& Qadir, 2015). However, proper planning is needed to implement these approaches.

Farmers get ample of benefits by applying the sustainable land management technique in the form of soil conservation, intensification, improvement in tillage regimes and biodiversity conservation. When the terraces, grass strips and bunds are constructed farmers get benefit by conserving the soil, as the soil is not wasted and cost of erosion is also avoided. Even many studies have been conducted on this benefit. Although, it varies according to each area specifications (Stringer, Fleskens, Reed, de Vente, \& Zengin, 2014).

Past literature has demonstrated that the installation of reduced tillage regimes is proved to benefit farmers. As it incurs less investments than terraces. Land managers till the seedbeds and control the diseases and pests in the crop field and work on mineralization to improve the quality of soil. As the nutrients reach the soil, the quality of the soil gets enhanced, which in result helps to grow apples, apricots, lentils, faba-beans and vegetables. Other than this, run-off and erosion are also reduced in the fields (Wickama, Okoba, \& Sterk, 2014). However, the production from tillage regimes are different in every region and can have different effect on the soil structure and requirement of labor.

Another benefit of SLM is the intensification of capital, pesticides, feeds, labor, residue of crops and minerals etc. to increase the output of land. By combing the practices of agronomic with the practice of sustainable land management, the nutrients of soil are increased only. The appropriate usage of non-organic or organic fertilizers increases the long-term productivity of the soil structure. Farmers can modify the system of farming to achieve greater output from the land (Wolfgramm, Shigaeva, \& Dear, 2015). Intensification also includes irrigation system which artificially provides water to all the fields and then generates greater output. As through irrigation dry lands are also cultivated so farmers can grow cash crops on those lands and then earn money. However, many further factors affect the productivity of the soil structure and irrigation may not help to change the structure of soil.

One more benefit of SLM is the biodiversity conservation. As farmers can do farming in different environments and also special kind of foods can be produced (Wossen, Berger, \& Di Falco, 2015). Moreover, the genetic resources of plant are not available at one farm so they need to be exchanged, thus a diverse population is needed. Yet, harsh environment may not help to gain needed genetic material from the farms.

The benefits of sustainable land management on global level includes climate mitigation, carbon retention, genetic materials' conservation, and albedo and flood prevention (Zou \& Wu, 2017). The amount of carbon can be easily measured in the environment and also flood can be controlled when the soil structure remains strong enough. Nonetheless, to avail these benefits farmers have to invest a lot.

By adapting sustainable land management, farmers and land managers have to incur costs as well. The cost of credit and opportunity cost are incurred when this practice is executed according to different researchers (Xie, Zou, Jiang, Zhang, \& Choi, 2014). If the credit is unavailable then farmers cannot avail the approaches of SLM, so the cost of borrowing and interest rates are higher to bear. Moreover, when the labor is available even during non-productive period then opportunity cost of labor increases. However, both the opportunity cost and labor credit cost are in accordance with each area.

Another cost which farmers bear is the external assistance cost (de Vente, Reed, Stringer, Valente, \& Newig, 
2016). Farmers cannot invest in huge amount so they take loans from financial institutions. Then after some time they return the principal amount along with its interest or mark-up amount. However, the interest rates vary from one financial institution to another.

Then another cost is labor cost which is incurred at the time of installation of sustainable land management activity. Then costs of land degradation are also incurred when opting the SLM program. The positive results from sustainable land management are achieved after a period of time but land degradation costs are incurred immediately, so it's a crucial problem for farmers to wait that long (Aragon et al., 2017; Asrat \& Simane, 2017). Yet, many other costs are born by farmers.

\section{Material and Methods}

The research design, research philosophy, research approach, time zone, study population, sampling, data collection, sampling size, questionnaires, validity and ethical considerations has been enlisted with discrete advantages and disadvantages. The exploratory research design is used in this study to do the comparative analysis of costs and benefits of SLM. This type research design is used to find the new knowledge regarding the sustainable land management. Researchers have demonstrated that exploratory research helps to get different opinions and views of different people (Reference). It is further highlighted that it assists in exploring all the ways in which costs are incurred. This design is implemented to accomplish the objectives and goals of this study. It further intervenes the economic viability of SLM with respect to higher benefits and comparatively less costs.

The research philosophy which is used in this study is positivism because researchers are not interfering in it. In this type of study, data is quantifiable and the researcher's role is limited to interpretation and data collection. Statistical analysis is done in this study on quantifiable observations. Moreover, the positivism philosophy states that researchers should focus on facts rather than on opinions.

The deductive approach is used in this study to highlight that study attributes from general to specific. Moreover, it is based on the hypothesis so research strategy is formed according to it. The advantages of this approach are that concepts are measured quantitatively and also relationships among variables and concepts are explained thoroughly. The quantitative method is used to analyze the data by focusing on the numerical and statistical analysis of the data, which is collected through surveys, polls and questionnaires. It collects the numerical data to explain a particular subject or phenomena. The method is used to compare the benefits of SLM with its costs.

In order to collect the data relevant to this study, the residents of Mali (Please write the GPS map of area) are selected. The farmers or people regarding to agriculture field are the study population of this research. The study population are those people who are been selected as the sample of the study. The local people were selected as sample of the study because they may be aware of the costs and benefits of the sustainable land management. According to some researchers, sampling means selecting some of the people who will represent the whole population in a study. This study has used the purposive sampling, it means that the sample is being selected in accordance with the objectives of study and the required traits of the study population. To collect the data, 176 participants are selected in this study.

The data was collected through both primary and secondary ways to improve the validity of this research paper. Investigators have enlightened that questionnaire contains a number of different questions, both open-ended and close-ended, related to the research topic. Different options are also given along with the questions and respondents chose the best option which suits them. In this study, a self-constructed questionnaire was used to obtain the data from the sample. Each questionnaire contained 12 questions in total and 9 questions were in objective phase and 3 questions were in demographic phase. The total 150 questionnaires were filled out from local people of Mali though different mediums and then were overseen by the researchers to check its validity. The ethical values were observed in this study proficiently. Informed consent was taken from the participants before filling out the questionnaires. Moreover, the privacy of respondents was also maintained and the data collected from them were not made public.

\subsection{Results}

4.1 Demographic Analysis

In Mali, mostly males were found to be engaged in sustainable land management (SLM). The sample containing 176 individuals revealed that there were $68.2 \%$ males and only $31.8 \%$ females (Fig $1 \mathrm{~A}$ ). It was found out that males paid more attention on the practice of SLM and compared its benefits against its costs. It also explains the gender-based specificity that females are opt to do household and less sensitive jobs and more sensitive and complicated work of SLM is done by males. 


\section{Figures}

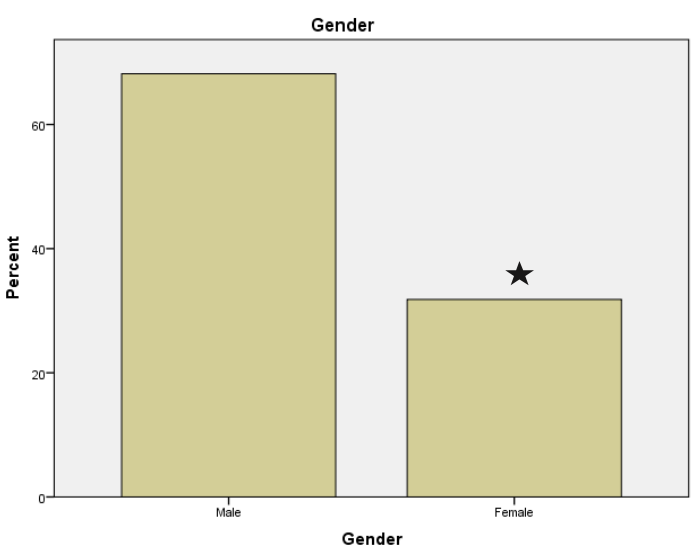

A

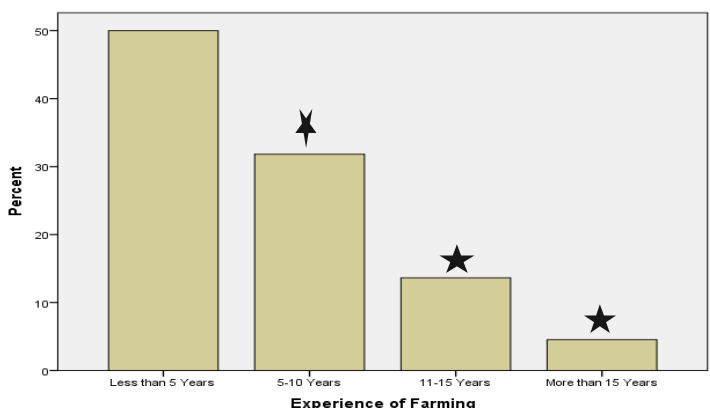

C

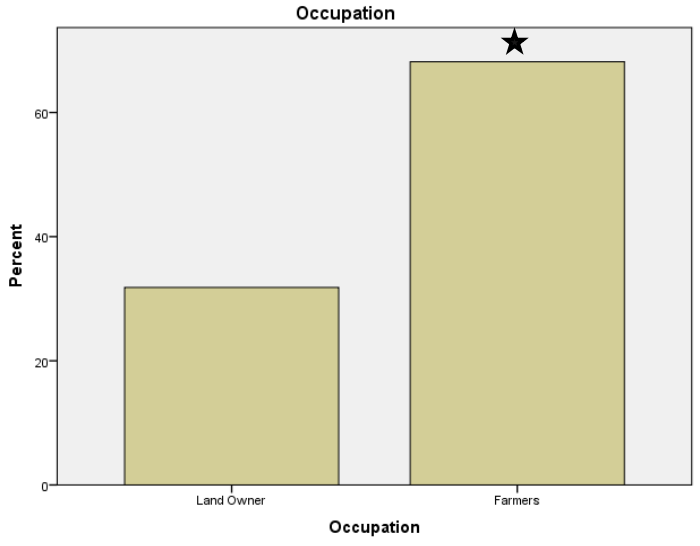

B

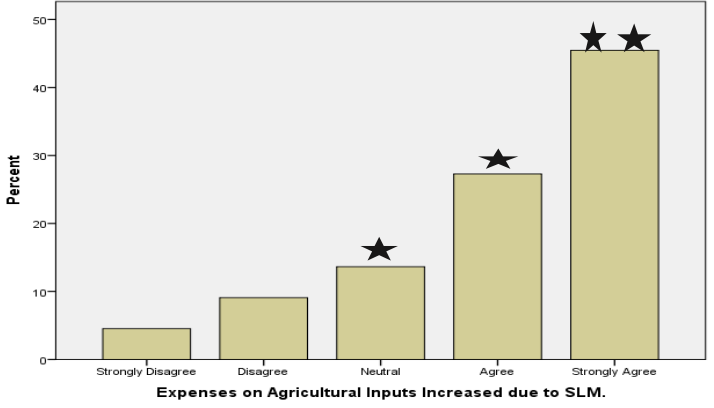

D

Fig. 1. (A)The gender based engaament of indiciduals in sustainabale land management. (B) The distribution of occupation of sample population. (C) The duration of farming experience of individuals practicing sustainable land management. (D) The survey of samples mindset towards the SLM as the basic cause for increasing the agricultural inputs.

The occupation of most of the samples was farmers instead of land owners. The $68.2 \%$ of the sample population was farmers whereas only $31.8 \%$ was land owners (Fig. 1B). The findings presented that land owners were not interested in applying the practice of SLM, they only owned the land. But farmers were seriously concerned to know the economic viability of sustainable land management and analyzed its benefits and costs to get more profit as they have to give the fixed share/profit to land owners.

The results exposed that the experience of farming of the 50\% sample was less than 5 years. But $31.8 \%$ had an experience of farming of 5-10 years while only $13.6 \%$ had an experience of 11-15 years (Fig-1C). The majority of individuals (farmers and land owners) might not be aware regarding the SLM practice and its benefits and costs due to less experience. This trend highlights the increasing trend of farmers to adopt the SLM for improvement and better household.

\subsection{Descriptive Costs and Benefits Analysis}

The $45.5 \%$ of sample population was strongly agreed that expenses on agricultural inputs increased due to SLM while only $4.5 \%$ strongly disagreed with the given statement (Fig 1D). It was demonstrated that land owners and farmers had to bear expenses and costs while implementing the strategy of SLM (Tab 1). According to them, the costs of SLM are greater than its benefits but in long run it will give more benefits to sustainable agriculture. Similarly, $13.6 \%$ gave a neutral answer.

Table-1. The farmers consideration of SLM as the reason for increasing the cost of agricultural inputs

\begin{tabular}{llrrrr}
\hline & Frequency & Percent & Valid Percent & Cumulative Percent \\
\hline \multirow{6}{*}{ Valid } & 8 & 4.5 & 4.5 & 4.5 \\
& Strongly Disagree & 16 & 9.1 & 9.1 & 13.6 \\
& Disagree & 24 & 13.6 & 13.6 & 27.3 \\
& Neutral & 48 & 27.3 & 27.3 & 54.5 \\
& Agree & 80 & 45.5 & 45.5 & 100.0 \\
& Strongly Agree & 176 & 100.0 & 100.0 & \\
\hline
\end{tabular}

According to the sample, $36.4 \%$ agreed that farm income has been increased due to SLM but 9.1\% strongly disagreed with the question (Fig 2A. Tab-2). The findings proved that benefits of SLM were more than its costs 
as it aided the farmers as well as land owners to get benefits from it in the form of diversity, productivity and shortterm returns etc.

Table-2. The farmers views toward the farm income increased due to SLM

\begin{tabular}{llllll}
\hline & & Frequency & Percent & Valid Percent & Cumulative Percent \\
\hline Valid & Strongly Disagree & 16 & 9.1 & 9.1 & 9.1 \\
& Disagree & 24 & 13.6 & 13.6 & 22.7 \\
& Neutral & 16 & 9.1 & 9.1 & 31.8 \\
& Agree & 64 & 36.4 & 36.4 & 68.2 \\
& Strongly Agree & 56 & 31.8 & 31.8 & 100.0 \\
& Total & 176 & 100.0 & 100.0 & \\
\hline
\end{tabular}

$59.1 \%$ sample disagreed that diversity of income has decreased due to SLM. But $9.1 \%$ gave a neutral response whereas only $4.5 \%$ strongly agreed with the statement (Fig 2B).

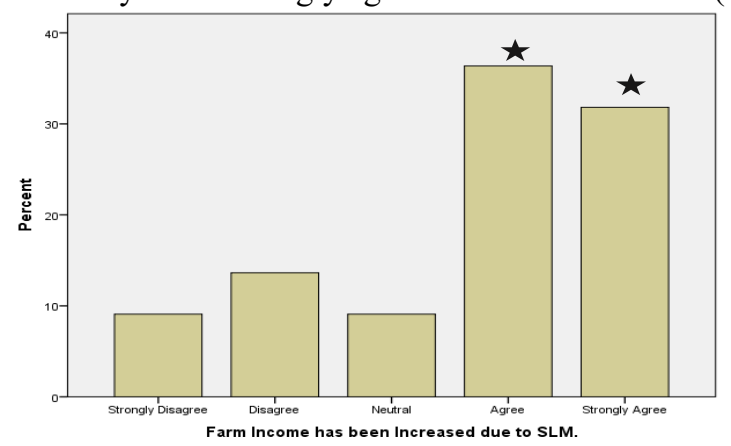

A

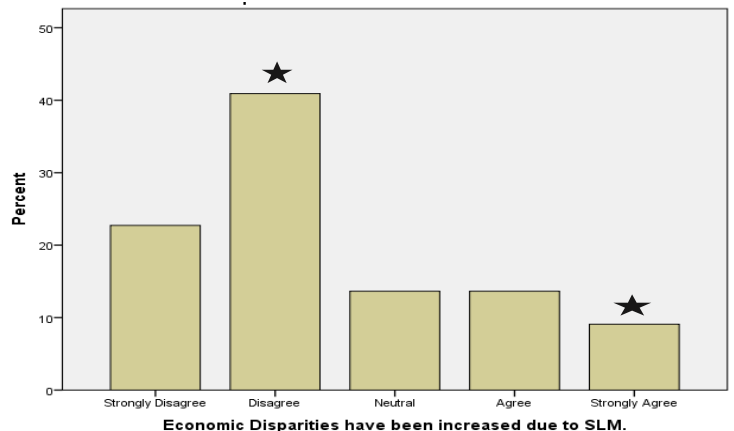

$\mathrm{C}$

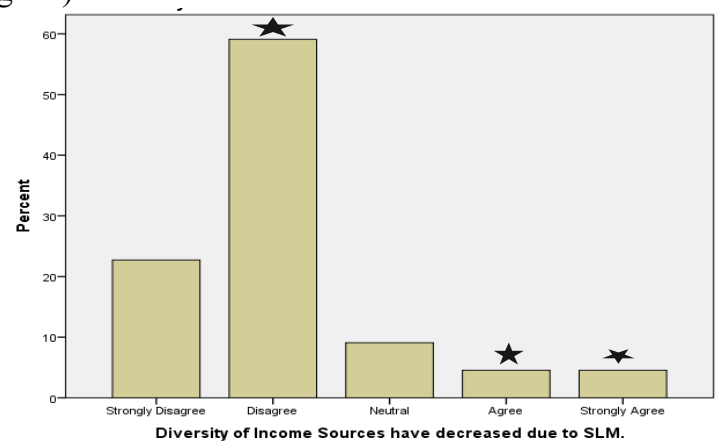

B

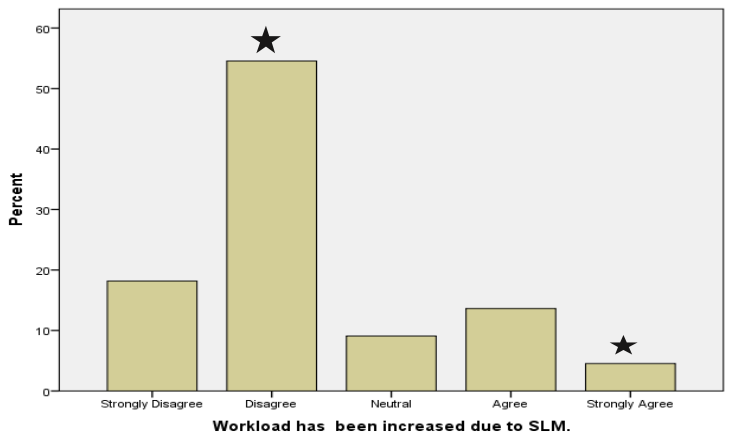

D

Fig. 2. (A) The distribution of farm income due to the application of SLM. (B) The sample population response towards the decrease of income source diversity due to SLM. (C) The economic disparities increased due to SLM. (D) Work load has been increased due to SLM

The results presented that by using the SLM approach, diversity of income increased rather than decreased. So, it discovered that its cost $\mathrm{x}$ was less than its benefits (tab 3).

Tab-3. The farmers consideration toward the decrease of income source diversity due to SLM

\begin{tabular}{llrrrr}
\hline & Frequency & Percent & Valid Percent & Cumulative Percent \\
\hline \multirow{6}{*}{ Valid } & 40 & 22.7 & 22.7 & 22.7 \\
& Strongly Disagree & 104 & 59.1 & 59.1 & 81.8 \\
& Disagree & 16 & 9.1 & 9.1 & 90.9 \\
& Neutral & 8 & 4.5 & 4.5 & 95.5 \\
& Agree & 8 & 4.5 & 4.5 & 100.0 \\
& Strongly Agree & 176 & 100.0 & 100.0 & \\
\hline
\end{tabular}

Among the sample of $176,40.9 \%$ disagreed that economic disparities have been increased by opting the SLM approach (Fig 2C). Only 9.1\% strongly agreed but $13.6 \%$ provided a neutral answer because they were not aware about the costs and benefits of SLM. But those who disagreed knew that economic disparities did not increase due to SLM. Similarly, $22.7 \%$ strongly disagreed while $13.6 \%$ agreed in accordance with their experiences (Tab-4). 
Tab-4. The farmers consideration toward the increase of economic disparities due to SLM

\begin{tabular}{llrrrr}
\hline & Frequency & Percent & Valid Percent & Cumulative Percent \\
\hline \multirow{6}{*}{ Valid } & 40 & 22.7 & 22.7 & 22.7 \\
& Strongly Disagree & 72 & 40.9 & 40.9 & 63.6 \\
& Disagree & 24 & 13.6 & 13.6 & 77.3 \\
& Neutral & 24 & 13.6 & 13.6 & 90.9 \\
& Agree & 16 & 9.1 & 9.1 & 100.0 \\
& Strongly Agree & 176 & 100.0 & 100.0 & \\
\hline
\end{tabular}

$54.5 \%$ respondents from the sample disagreed that workload has been increased because of executing the SLM approach (Fig 2D). Nonetheless, 9.1\% furnished a neutral answer for the given question while only $4.5 \%$ strongly agreed that workload increased. It was exposed by the results that SLM reduced the workload of farmers by improving the soil structure and by intensifying the capital, feeds, seeds and minerals in the fields Tab-5).

Tab-5. The farmers consideration of SLM as the reason of increasing the work load of the farms

\begin{tabular}{llrrrr}
\hline & Frequency & Percent & Valid Percent & Cumulative Percent \\
\hline \multirow{4}{*}{ Valid } & 32 & 18.2 & 18.2 & 18.2 \\
& Strongly Disagree & 96 & 54.5 & 54.5 & 72.7 \\
& Disagree & 16 & 9.1 & 9.1 & 81.8 \\
& Neutral & 24 & 13.6 & 13.6 & 95.5 \\
& Agree & 8 & 4.5 & 4.5 & 100.0 \\
& Strongly Agree & 176 & 100.0 & 100.0 & \\
\hline
\end{tabular}

From the above results, we got to know that $40.9 \%$ disagreed that short-term returns are significantly higher than the establishment cost of SLM (Fig 3A).

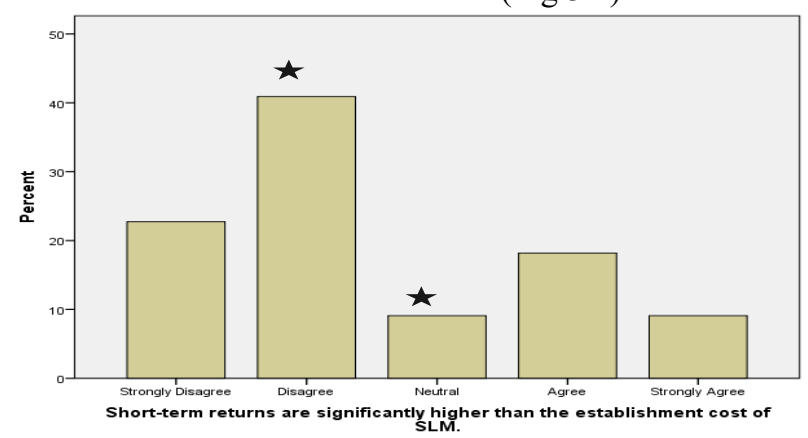

A

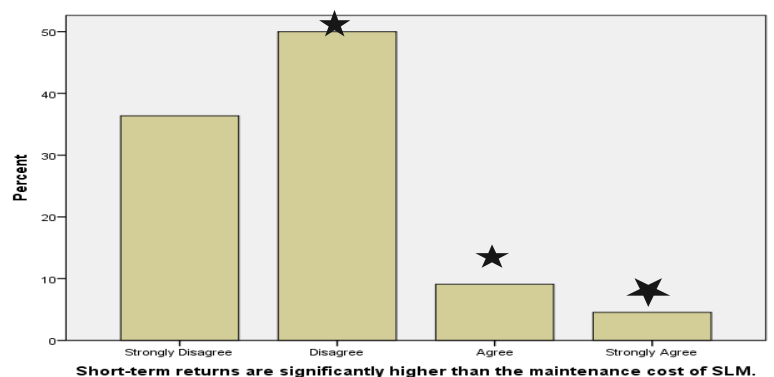

$\mathrm{C}$

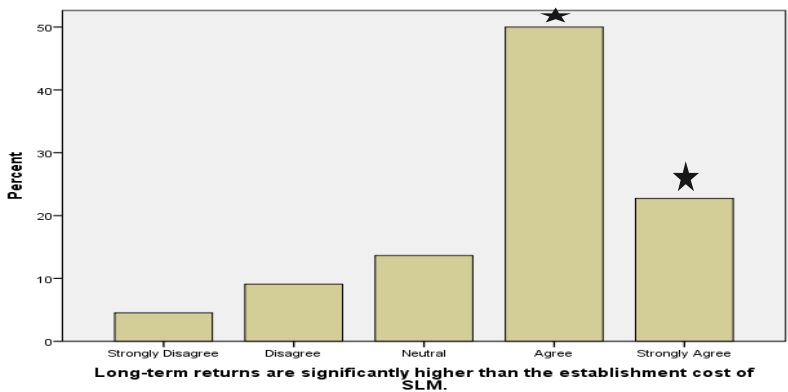

$\mathrm{B}$

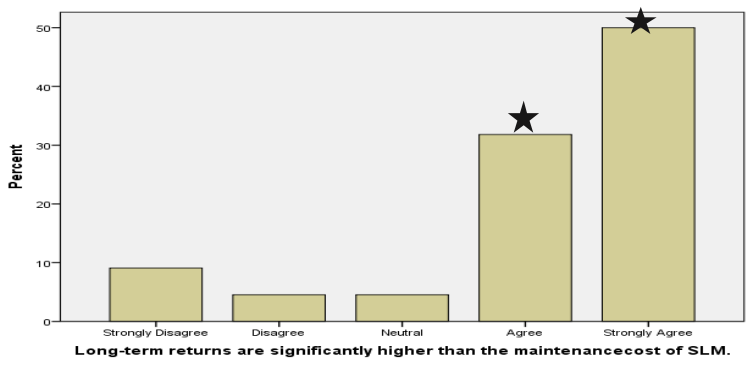

D

Fig. 3, (A) Short term returns are significantly higher than the establishment cost of SLM. (B) long terms returns are significantly higher than the establishment cost of SLM. (C) Short term returns are significantly higher than the maintenance cost of SLM. (D) Long-term returns are significantly higher than the maintenance of SLM.

However, $18.2 \%$ agreed with that but $9.1 \%$ simply gave a neutral answer. It was brought into sight that farmers believed that the initial cost of establishing SLM was much higher than its short-term profits or returns.

Tab-6. The short-term returns are significantly higher than the establishment cost of SLM

\begin{tabular}{rlrrrr}
\hline & Frequency & Percent & Valid Percent & Cumulative Percent \\
\hline \multirow{6}{*}{ Valid } & Strongly Disagree & 40 & 22.7 & 22.7 & 22.7 \\
& Disagree & 72 & 40.9 & 40.9 & 63.6 \\
& Neutral & 16 & 9.1 & 9.1 & 72.7 \\
& Agree & 32 & 18.2 & 18.2 & 90.9 \\
& Strongly Agree & 16 & 9.1 & 9.1 & 100.0 \\
& Total & 176 & 100.0 & 100.0 & \\
\hline
\end{tabular}

The $50 \%$ participants of the study agreed that long-term returns are significantly higher than the SLM's 
establishment cost (Fig 3B). Although, 4.1\% strongly disagreed with question and $13.6 \%$ gave a neutral response because they might not be able to analyze its costs and benefits. However, the judgements had shown that farmers were able to look beyond the establishment cost of SLM and were aware that in future SLM would benefit them in different ways.

Tab. 7. Long term returns are significantly higher than the establishment cost of SLM

\begin{tabular}{llrrrr}
\hline & Frequency & Percent & Valid Percent & Cumulative Percent \\
\hline \multirow{6}{*}{ Valid } & 8 & 4.5 & 4.5 & 4.5 \\
& Strongly Disagree & 16 & 9.1 & 9.1 & 13.6 \\
& Disagree & 24 & 13.6 & 13.6 & 27.3 \\
& Neutral & 88 & 50.0 & 50.0 & 77.3 \\
& Agree & 40 & 22.7 & 22.7 & 100.0 \\
& Strongly Agree & 176 & 100.0 & 100.0 & \\
\hline
\end{tabular}

The results from the above figure and table highlighted that 50\% sample disagreed that short-term returns are higher than the maintenance cost of SLM (Fig 3C). But the remaining respondents of the study gave different responses according to their knowledge and farming experiences such as $4.5 \%$ strongly agreed, $9.1 \%$ agreed and $36.4 \%$ strongly disagreed. The 50\% sample had an awareness that SLM's maintenance cost was higher than then its short-term profit.

$50 \%$ respondents from the sample of the study strongly agreed that long term returns and benefits of SLM are higher than its maintenance cost (Fig 3D). However, 9.1\% strongly disagreed $4.5 \%$ responded with a neutral answer. The most of the sample had analyzed the SLM's benefits against its costs and believed that its benefits were expected to be greater than its costs.

\section{Discussion}

The findings from the data analysis revealed that farmers were aware that expenses increased by using the SLM. Moreover, it was found out that short term profits were not higher than the cost of setting SLM and also the maintenance cost of it was higher than its short-term returns. Previous researchers (Barkemeyer, Stringer, Hollins, \& Josephi, 2015) have shown that farmers were aware that the benefits of SLM against its costs were less. They were able to identify the costs of SLM which was incurred on them (Fleskens, Nainggolan, \& Stringer, 2014) .

Tab.-8 Short-term returns are significantly higher than the maintenance cost of SLM

\begin{tabular}{rlrrrr}
\hline & \multicolumn{2}{c}{ Frequency } & \multicolumn{1}{c}{ Percent } & Valid Percent & Cumulative Percent \\
\hline \multirow{4}{*}{ Valid } & Strongly Disagree & 64 & 36.4 & 36.4 & 36.4 \\
& Disagree & 88 & 50.0 & 50.0 & 86.4 \\
& Agree & 16 & 9.1 & 9.1 & 95.5 \\
& Strongly Agree & 8 & 4.5 & 4.5 & 100.0 \\
& Total & 176 & 100.0 & 100.0 & \\
\hline
\end{tabular}

The data analysis's results demonstrated that farmers were able to analyze the benefits of SLM. Most of the sample stated that income was increased by implementing SLM. Past studies (Jendoubi et al., 2015) also showed the same findings. Moreover, farmers also knew that diversity of sources also increased because of SLM and that was beneficial for them both in the short run and long run (Gunawardana, Tantrigoda, \& Kumara, 2016).

Tab-9 Long term returns are significantly higher than the maintenance const of SLM

\begin{tabular}{rlrrrr}
\hline & Frequency & Percent & Valid Percent & Cumulative Percent \\
\hline \multirow{6}{*}{ Valid } & Strongly Disagree & 16 & 9.1 & 9.1 & 9.1 \\
& Disagree & 8 & 4.5 & 4.5 & 13.6 \\
& Neutral & 8 & 4.5 & 4.5 & 18.2 \\
& Agree & 56 & 31.8 & 31.8 & 50.0 \\
& Strongly Agree & 88 & 50.0 & 50.0 & 100.0 \\
& Total & 176 & 100.0 & 100.0 &
\end{tabular}

The farmers and land owners were found to be comparing the costs and benefits of SLM. They compared both the short-term and long-term returns with the maintenance cost and establishment cost of SLM. They were aware that workload did not increase with the SLM approach but rather it helped them to do farming more efficiently and effectively. The previous researchers also found out the same things related to this particular topic (Nkonya, Mirzabaev, \& Von Braun, 2016; Popović et al., 2015).

\section{Conclusion and future aspects}

From conception to its completion, the major goal of the study was to analyze the benefits and costs of SLM and also to know if the SLM was economically viable. Then literature review provided the details of concept, functions, approaches and analysis of costs and benefits of SML. Then survey methodology was used in this study and questions were asked related to costs and benefits of SLM from the residents of Mali. Finally, the findings from data analysis reflected that people of Mali were aware regarding the benefits and costs of SLM. 
The theoretical implication is that this study has provided theoretical support through its benefits and costs analysis. Moreover, this study has also increased the literature review in this particular domain. The empirical evidence which is collected from the quantitative analysis has created concreteness in the arguments of the study, so by using that concreteness other researchers can propose various theories on SLM. The practical implication in this study is that it helps the farmers and land owners in farming to increase their profits, returns and production through SLM. They will get to know that efforts in farming are reduced by using the SLM approach and also through this, their productivity in farming will become enhanced. Moreover, different farming industries will change its working patterns when they come to know that its benefits are more than its costs and then will eventually adapt SLM.

Government can use this study to apply one rule or policy on all farmers to use SLM. This way all farming will be executed in the same way. Besides, economy will grow and prosper by increasing its GDP. This study consists of a number of limitations. The first limitation in this study was the sample size. The sample which was selected was quite small, so the findings found out could not be generalized to the whole population. Moreover, if the sample size was large enough then different opinions could have been gained and validity and reliability of the study would have been maintained. Another limitation in this study is that quantitative method was used to analyze the results. Quantitative method only quantified the results but failed to provide a descriptive analysis. Then this study was cross-sectional and was conducted only once which meant that it failed to get opinions from the respondents over a period of time. In addition, this study only revolved around the costs and benefits analysis of SLM and ignored all other aspects. Then this study also lacks mediators and moderators, another limitation of the study.

\section{Acknowledge}

This study was funded by Huazhong University of Science and Technology (HUST) with the scholarship of the People's Republic of China offered to my country Mali which I am beneficiary thanks to a strong friendship of more than 50 years. The authors have no conflict of interest between them. This is the place to thank the Teachers of my department and especially my supervisor for his support and advice without which this work would not be possible, I also thank my compatriots in Mali who helped me for the collection of data.

\section{References}

Almagro, M., de Vente, J., Boix-Fayós, C., García-Franco, N., De Aguilar, J. M., González, D., . . . MartínezMena, M. (2016). Sustainable land management practices as providers of several ecosystem services under rainfed Mediterranean agroecosystems. Mitigation and adaptation strategies for global change, 21(7), 10291043.

Aragon, N. U., Wagner, M., Wang, M., Broadbent, A. M., Parker, N., \& Georgescu, M. (2017). Sustainable land management for bioenergy crops. Energy Procedia, 125, 379-388.

Asrat, P., \& Simane, B. (2017). Adapting smallholder agriculture to climate change through sustainable land management practices: empirical evidence from North-West Ethiopia. J Agric Sci Technol A, 7(2017), 289301.

Barkemeyer, R., Stringer, L. C., Hollins, J. A., \& Josephi, F. (2015). Corporate reporting on solutions to wicked problems: Sustainable land management in the mining sector. Environmental science \& policy, 48, $196-209$.

Bertin, T., Zacharie, T., Ann, D., Ebenezar, A., \& Alain, T. (2014). Scaling-up sustainable land management practices through the concept of the rural resource centre: reconciling farmers' interests with research agendas. The Journal of Agricultural Education and Extension, 20(5), 463-483.

Brevik, E. C., Pereira, P., Muñoz-Rojas, M., Miller, B. A., Cerdà, A., Parras-Alcántara, L., \& Lozano-García, B. (2017). Historical perspectives on soil mapping and process modeling for sustainable land use management Soil Mapping and Process Modeling for Sustainable Land Use Management (pp. 3-28): Elsevier.

de Vente, J., Reed, M. S., Stringer, L. C., Valente, S., \& Newig, J. (2016). How does the context and design of participatory decision making processes affect their outcomes? Evidence from sustainable land management in global drylands. Ecology and Society, 21(2).

Duval, M. E., Galantini, J. A., Martínez, J. M., López, F. M., \& Wall, L. G. (2016). Sensitivity of different soil quality indicators to assess sustainable land management: Influence of site features and seasonality. Soil and Tillage Research, 159, 9-22.

Fleskens, L., Nainggolan, D., \& Stringer, L. C. (2014). An exploration of scenarios to support sustainable land management using integrated environmental socio-economic models. Environmental management, 54(5), 1005-1021.

Giger, M., Liniger, H., Sauter, C., \& Schwilch, G. (2018). Economic benefits and costs of sustainable land management technologies: an analysis of WOCAT's global data. Land degradation \& development, 29(4), 962-974.

Gray, J. M., Chapman, G. A., \& Murphy, B. W. (2015). Land management within capability: a new scheme to 
guide sustainable land management in New South Wales, Australia. Soil Research, 53(6), 683-694.

Gunawardana, H., Tantrigoda, D. A., \& Kumara, U. (2016). Humanitarian Demining and Sustainable Land Management in Post-Conflict Settings in Sri-Lanka: Literature Review. J. Mgmt. \& Sustainability, 6, 79.

Halbac-Cotoara-Zamfir, R., Herban, S., Petursdottir, T., \& Finger, D. (2017). Innovative sustainable land management practices for landscapes under climate changes threats. Paper presented at the Proceedings of the 45th International Symposium on Agricultural Engineering, Actual Tasks on Agricultural Engineering, 21-24 February 2017, Opatija, Croatia.

Jendoubi, D., Schwilch, G., Liniger, H., Hurni, H., Ouessar, M., Moussa, M., \& Hamrouni, H. (2015). Assessment of land degradation in the Cereal land use and options for sustainable land management: Study case from Northwest Tunisia.

Kapur, S., Eswaran, H., \& Blum, W. (2014). Sustainable land management: Springer.

Keesstra, S. D., Bouma, J., Wallinga, J., Tittonell, P., Smith, P., Cerdà, A., . . . van der Putten, W. H. (2016). The significance of soils and soil science towards realization of the United Nations Sustainable Development Goals. Soil, 2(2), 111-128.

Kundzewicz, Z., \& Kowalczak, P. (2014). Urban Flooding and Sustainable Land Management-Polish Perspective.

Liniger, H., Mekdaschi, R., Moll, P., \& Zander, U. (2017). Making sense of research for sustainable land management: Centre for Development and Environment (CDE), University of Bern and Helmholtz-Centre for Environmental Research GmbH-UFZ.

Maisharou, A., Chirwa, P., Larwanou, M., Babalola, F., \& Ofoegbu, C. (2015). Sustainable land management practices in the Sahel: review of practices, techniques and technologies for land restoration and strategy for up-scaling. International Forestry Review, 17(3), 1-19.

Marques, M. J., Bienes, R., Cuadrado, J., Ruiz-Colmenero, M., Barbero-Sierra, C., \& Velasco, A. (2015). Analysing perceptions attitudes and responses of winegrowers about sustainable land management in Central Spain. Land degradation \& development, 26(5), 458-467.

Mutoko, M. C., Hein, L., \& Shisanya, C. A. (2014). Farm diversity, resource use efficiency and sustainable land management in the western highlands of Kenya. Journal of rural studies, 36, 108-120.

Nkonya, E., Mirzabaev, A., \& Von Braun, J. (2016). Economics of land degradation and improvement: a global assessment for sustainable development: Springer.

Nkonya, E., \& Pender, J. L. (2015). Strategies for sustainable land management in Uganda.

Pereira, P., Brevik, E. C., Muñoz-Rojas, M., Miller, B. A., Smetanova, A., Depellegrin, D., . . Cerdà, A. (2017). Soil Mapping and Processes Modeling for Sustainable Land Management Soil mapping and process modeling for sustainable land use management (pp. 29-60): Elsevier.

Pidlisnyuk, V., Erickson, L., Kharchenko, S., \& Stefanovska, T. (2014). Sustainable land management: growing miscanthus in soils contaminated with heavy metals. Journal of Environmental Protection, 5(08), 723.

Plieninger, T., Bieling, C., Fagerholm, N., Byg, A., Hartel, T., Hurley, P., . . . Raymond, C. M. (2015). The role of cultural ecosystem services in landscape management and planning. Current Opinion in Environmental Sustainability, 14, 28-33.

Popović, V., Miljković, J. Ž., Subić, J., Jean-Vasile, A., Adrian, N., \& Nicolăescu, E. (2015). Sustainable land management in mining areas in Serbia and Romania. Sustainability, 7(9), 11857-11877.

Reed, M., Stringer, L., Dougill, A., Perkins, J., Atlhopheng, J., Mulale, K., \& Favretto, N. (2015). Reorienting land degradation towards sustainable land management: Linking sustainable livelihoods with ecosystem services in rangeland systems. Journal of environmental management, 151, 472-485.

Sanz, M., De Vente, J., Chotte, J.-L., Bernoux, M., Kust, G., Ruiz, I., . . . Castillo, V. (2017). Sustainable land management contribution to successful land-based climate change adaptation and mitigation: a report of the Science-Policy Interface.

Schwilch G, Liniger HP, Hurni H. 2014. Sustainable land management (SLM) practices in drylands: how do they address desertification threats? Environmental Management 54: 983-1004.

Stringer, L., Fleskens, L., Reed, M., de Vente, J., \& Zengin, M. (2014). Participatory evaluation of monitoring and modeling of sustainable land management technologies in areas prone to land degradation. Environmental management, 54(5), 1022-1042.

Teshome, A., de Graaff, J., Ritsema, C., \& Kassie, M. (2016). Farmers' perceptions about the influence of land quality, land fragmentation and tenure systems on sustainable land management in the north western Ethiopian Highlands. Land degradation \& development, 27(4), 884-898.

Wichelns, D., \& Qadir, M. (2015). Achieving sustainable irrigation requires effective management of salts, soil salinity, and shallow groundwater. Agricultural Water Management, 157, 31-38.

Wickama, J., Okoba, B., \& Sterk, G. (2014). Effectiveness of sustainable land management measures in West Usambara highlands, Tanzania. Catena, 118, 91-102.

Wolfgramm, B., Shigaeva, J., \& Dear, C. (2015). The research-action interface in sustainable land management in Kyrgyzstan and Tajikistan: challenges and recommendations. Land degradation \& development, 26(5), 
480-490

Wossen, T., Berger, T., \& Di Falco, S. (2015). Social capital, risk preference and adoption of improved farm land management practices in Ethiopia. Agricultural Economics, 46(1), 81-97.

Xie, H., Zou, J., Jiang, H., Zhang, N., \& Choi, Y. (2014). Spatiotemporal pattern and driving forces of arable landuse intensity in China: Toward sustainable land management using emergy analysis. Sustainability, 6(6), 3504-3520.

Zou, J., \& Wu, Q. (2017). Spatial Analysis of Chinese Grain Production for Sustainable Land Management in Plain, Hill, and Mountain Counties. Sustainability, 9(3), 348. 